\title{
Katılma Nöbetlerinin Etiyolojisinde Yumuşak Damak Evrelemesinin ve Palatintonsil Hipertrofinin Önemi
}

\section{The Importance of Palatitonsillar Hypertrophy and Soft Palate Staging in Etiology of Breathe Holding Spells}

\author{
Beril DILBER ${ }^{1}$, Ahmet URAL 2 , Tülay KAMAŞAK ${ }^{1}$, Ali CANSU1
}

${ }^{1}$ Karadeniz Teknik Üniversitesi, Tıp Fakültesi, Çocuk Sağlığı ve Hastalıkları Anabilim Dalı, Çocuk Nöroloji Bilim Dalı, Trabzon, Türkiye

${ }^{2}$ Karadeniz Teknik Üniversitesi, Tıp Fakültesi, Kulak Burun Boğaz Bilim Dalı, Trabzon, Türkiye

\section{Öz}

Amaç: Katılma nöbeti çocukluk yaş grubunda görülen epileptik olmayan paroksismal bir olaydır. Patofizyolojisi tam olarak aydınlatılamamıştır. Hipoksi neden ya da sonuç olsa da hipoksinin çocukta yaptığı hasar önemlidir ve maruziyeti azaltılmalıdır. Bizim çalışmamız katılma nöbeti olan çocuklarda palatintonsil hipertrofisinin ve yumuşak doku evrelemesinin katılma nöbeti üzerine etkisini ve ilişkisini göstermeyi amaçlayan ilk çalışmadır.

Gereç ve Yöntemler: 2012-2016 yılları arasında en az bir senedir takipli demir eksikliği anemisi olmayan ve sık enfeksiyon geçirmeyen 8-56 ay arasında toplam 90 çocuk (katılma nöbeti olan/kontrol: 45/45) retrospektif olarak tarandı ve çalışmaya dahil edildi. Katılma nöbeti tanısı hikaye ve klinik gözlemlerinden ve videolardan konuldu. Katılma nöbeti olan hastaların yaşa ve cinsiyete göre atak süreleri, atak tipleri palatotonsil ve yumuşak damak evreleri kendi arasında ve kontrol grubu ile karşılaştııldı.

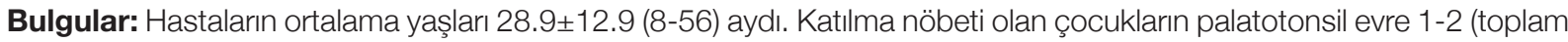
\%81.8) iken yumuşak damak evrelemeleri evre 2-3 (\%78.9)'di ve kontrol grubu ile anlamlı farklılık vardı (p: 0.000). Siyanotik tipte katılma nöbeti olan çocuklarda tonsil büyüklüğü evre 2-3'di ve tonsil büyüklüğü ile katılma nöbeti sıklığı arasında pozitif korelasyon vardı (r: 0.315, p: 0.032). Katılma nöbeti süresi ortalama $3.5 \pm 1.3$ dakikaydı. Palatotonsil büyüklüğü ve yumuşak damak evrelemesi ile atak süresi arasında da sırasıyla pozitif korelasyon mevcuttu (r: 0.459, p: 0.000; r: 0.734, p: 0,000).

Sonuç: Biz bu çalışmada; demir eksikliği anemisi olmayan ve sık enfeksiyon geçirmeyen katılma nöbeti olan çocuklarda kontrol grubuna oranla palatotonsil hipertrofinin belirgin olduğunu, ancak yumuşak damağın daha ileri evrelerde olduğunu gösterdik. Sonuç olarak katılma nöbeti etyolojisinde ve nöbet süresinin uzamasında bu hastalarda ileri evre yumuşak damak hipertrofisi olması riski 1.5 kat artırır ve erken müdahele ile akip gerektirir.

Anahtar Sözcükler: Katıma nöbeti süresi, Palatotonsil hipertrofisi evrelemesi, Yumuşak damak evrelemesi

ABSTRACT

Objective: Breath-holding spells (BHS) are common paroxysmal events in earlychildhood with unknown pathophysiology. Hypoxia can be the cause or result of BHS and the damage caused by hypoxia is of paramount importance. Therefore,

(1)

DILBER B : :0000-0002-7633-0060 URAL A : :0000-0002-6088-1415 KAMAŞAK T : :0000-0002-5212-0149 CANSU A : :0000-0002-1930-6312

\begin{abstract}
Çıkar Çatışması / Conflict of Interest: Tüm yazarlar adına, ilgili yazar çıkar çatıșması olmadığııı belirtir.
Etik Kurul Onayı / Ethics Committee Approval: Çalışma için, KTÜ Tıp Fakültesi, Bilimsel Araştırmalar Etik Kurul'undan 28.012019-2018-318 tarih ve numaralı onay alınmıştır.

Yazarların katkısı / Contribution of the Authors: DiLBER B: Araștırma ve/veya makalenin hipotezini veya fikrini olușturan, Sonuçlara ulașmak için planlama/ metodoloji belirleme, Araş̦tırma/çalıșmanın sorumluluğunu üstlenmek, ilerlemenin seyrini denetlemek, Sonuçların mantıksal olarak Yorumlanması ve sonuçlandııılması, Çalıșma için gerekli literatür taramasında sorumluluk almak, Çalıșmanın bütününün veya önemli bölümlerinin yazımında sorumluluk almak, Yazım ve dilbilgisi dışında bilimsel olarak gönderilmeden önce makaleyi gözden geçirme. URAL A: Araştırma ve/veya makalenin hipotezini veya fikrini oluşturan, Araştırma/çalıșmanın sorumluluğunu üstlenmek, ilerlemenin seyrini denetlemek. KAMAŞAK T: Sonuçlara ulaşmak için planlama/metodoloji belirleme, Araştırma/çalışmanın sorumluluğunu üstlenmek, ilerlemenin seyrini denetlemek, Hasta takibinde sorumluluk almak, ilgili biyolojik malzemelerin toplanması, veri yönetimi ve raporlama, deneylerin yürütülmesi, Sonuçların mantıksal olarak Yorumlanması ve sonuçlandırılması, Calıșma için gerekli literatür taramasında sorumluluk almak, Calıșmanın bütününün veya

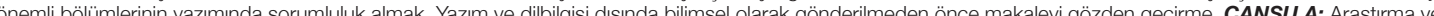
üstlenmek, ilerlemenin seyrini denetlemek, Sonuçların mantıksal olarak Yorumlanması ve sonuçlandırılması, Çalışma için gerekli literatür taramasında sorumluluk almak, Çalışmanın bütününün veya önemli bölümlerinin yazımında sorumluluk almak, Yazım ve dilbilgisi dışında bilimsel olarak gönderilmeden önce makaleyi gözden geçirme.

Atıf yazım șekli / How to cite : Dilber B, Ural A, Kamașak T, Cansu A. Katılma Nöbetlerinin Etiyolojisinde Yumușak Damak Evrelemesinin ve Palatintonsil Hipertrofinin Önemi. Türkiye Çocuk Hast Derg 2021;15:306-311.
\end{abstract}

Yazışma Adresi / Correspondence Address: Beril DILBER

Karadeniz Teknik Üniversitesi, Tıp Fakültesi, Çocuk Sağı̆̆ı ve Hastalıkları Anabilim Dalı, Çocuk Nöroloji Bilim Dalı, Trabzon, Türkiye

E-posta: beriltem@gmail.com
Geliş tarihi/ Received : : 10.02.2021 Kabul tarihi / Accepted : 16.03.2021 Elektronik yayın tarihi : 15.06 .2021 Online published

DOI: $10.12956 /$ tchd.874440 
exposure to hypoxia should be minimized in children with BHS. The present study, for the first time in the literature, investigated the staging of palatinetonsil and soft palate hypertrophy in children with BHS and their relationship with BHS.

Material and Methods: The retrospective study included 45 children with BHS with no iron deficiency and no complaints of frequent infections and had been followed up for a minimum of one year over between 2012 and 2016. A control group of 45 age-matched subjects. BHS was diagnosed based on patient history, clinical observations, and video records. Duration of spell, spell type, and the staging of palatinetonsil and soft palate hypertrophy were compared among the patients and with the control subjects in terms of age groups and genders.

Results: Mean age was 28.9 12.9 (range, 8-56) months in the BHS group. In the same group, the patients had stage 1-2 palatinetonsil hypertrophy (total $81.8 \%$ ) and stage 2-3 soft palate hypertrophy (78.9\%) and a significant difference was found between the BHS and control groups $(\mathrm{p}=0.000)$. In patients with cyanotic BHS, tonsillar hypertrophy was grade $2-3$ and a positive correlation was found between cyanotic BHS and tonsillar hypertrophy ( $r$ : 0.315, $\mathrm{p}=0.032$ ). Mean duration of spell was $3.5 \pm 1.3$ minand tonsillar hypertrophy established a stronger correlation with spell duration and soft palatinetonsil hypertrophy (r: 0.459, $p=0.000 ; r$ : 0.734, $p=0.000$, respectively).

Conclusion: The results indicated that the BHS patients with no iron deficiency and no complaints of frequent infections had greater palatinetonsil hypertrophy and a higher stage of soft palate hypertrophy compared to control subjects. We suggest that the presence of a high-stage soft palate hypertrophy increases the risk of developing BHS and the duration of spell by 1.5 times and thus requires early intervention and clinical follow-up.

Key Words: Breath-holding spell duration, Palatinetonsil hypertrophy, Soft-palate stage

\section{GiRiş}

Katılma nöbetleri çocukluk çağında sık karșılașılan epileptik olmayan paroksismal olaylardandır. Katıma nöbetleri toplumda \% 4-5 sıklıkta görülür tipik başlangıç yaşı 6-18 aydır. \% 10 iki yaşından sonra başlar. Nöbetlerin sıklığı gün içinde çok sayıda ataktan, yılda bir iki atak sayısına kadar değişkenlik gösterir. Katılma nöbetleri siyanotik, soluk tip olmak üzere iki grupta incelenir (1). Katılma nöbeti batı ülkelerinde \% 0.1-4.6 sıklığında raporlanmıştır, ülkemizde ise yapılan bir çalışma da ise sıklığı \%3.6 olarak bildirilmiştir (2). Katılma nöbetinin patofizyolojisi net olmamakla beraber katıma nöbetlerinin oluşumunda duygusal durumda değişiklik, acı ve korku sonrası postür kaybı ve bilinç kaybı ya da katılaşma şeklinde klinikte görülür. Etiyolojisinde ailesel yatkınlık, anne davranıșlarında farklılık gibi nedenler dışında demir eksikliği ve selenyum eksikliği bildirilmiştir (3-6). Asıl neden hipoksi ve bunun olası yan etkileridir. Hücresel düzeyde hipoksiyi tetikleyecek sadece demir eksikliği değil tüm etkenler bu çocuklarda araştırımalıdır. Havayolunun anatomik sorunları ayrıntılı muayenenin bir parçası olmalıdır. Tonsil hipertrofisi ve yumuşak damak patolojileri hava yolu obstrüksiyonlarının en sık nedenidir (7-9). Tonsiller, erken çocukluk döneminde olgunlaşmaya bașlar ve püberteye kadar devam eder. Daha sonra atrofik değișiklikler görülebilir. Bu değișimin nedeni kesin olarak bilinmemekle birlikte diyet, genetik, hümoral faktörlerin etkili olduğu düşünülmektedir. Lokal ya da sistemik enfeksiyon ataklarını takiben büyüme gösterebilirler. Tonsilin büyüklüğü mekanik obstrüksiyon, solunum ve yutma güçlüğü oluşturmadığı sürece klinik olarak önemi yoktur (10). Ancak özellikle siyanotik tip katılma nöbetlerinde sekonderhipoksi sıklıkla daha ağır bir şekilde görülmektedir (11). Biz bu çalışmamızda ilk defa katılma nöbeti olan çocuklarda yumuşak damak ve palatintonsil hipertrofisi ile bunların katıma nöbetlerine etkisini ve de arasındaki ilişkiyi göstermeyi amaçlamaktadır.

\section{GEREÇ ve YÖNTEMLER}

Çalışmaya 2012-2016 yılları arasında demir eksikliği anemisi olmayan en az bir senedir takipli ve sık enfeksiyon geçirmeyen, katılma nöbeti ile takip edilen yaşları 8-56 ay arasında değişen 45 hasta dahil edildi. Aynı yaş ve cinsiyette sağlıklı çocuk izlemine gelen 45 sağlıklı çocuktan kontrol grubu oluşturuldu. Toplam 90 çocuk hasta çalışmaya alındı. Çalışmaya katılan ailelerden imzalı onam formu, 2019/318 numaralı etik kurul onayı alındı.

\section{Çalışmaya Dahil Edilme Kriterleri;}

1. Kilo ve boy gelişimi normal (antropometrik ölçümleri normal olması), yetersiz beslenme veya vitamin eksikliği belirtisi olmayan, vitamin desteği almayan çocuklar

2. Fizik muayenesi ve görüntülemesi normal olan çocuklar

3. Rekürent tonsillit atağı geçirmeyen, ebebeynleri tarafından ağzı açık uyuduğu belirtilmeyen ve uyku apnesi olmayan

4. Hem siyanotik hem soluk tipte nöbeti olan çocuklar çalışmaya dahil edildi.

Bütün hastalara kardiyolojik muayene yapıldı, ekokardiyografi ve elektroensefalogram çekildi.

\section{Dışlanma Kriterleri:}

1. İlerleyici nörolojik hastalıklar, hipoksik iskemik ensefalopati sekeli, epilepsi, serebral palsi,

2. Akut veya kronik akciğer hastalıkları, kalp ve diğer kronik hastalıklar

3. Sık enfeksiyon geçiren, enfeksiyonlar nedeniyle antibiyotik tedavisi almak zorunda olunan çocuklar,

4. Anemisi olan ve tedavi gören çocuklar çalışma dışı bırakıldı.

Katılma nöbeti tanısı ailelerin hikayelerinden ve klinik gözlemlerinden ve gösterdikleri videolardan konuldu. Katılma nöbeti sıklığı ailelerin tuttuğu günlükten (nöbet sıklığı ve süresi) değerlendirildi. 
Katılma nöbeti sıklığı; her gün (günde bir kez), haftada iki gün (günde bir kez), haftada iki gün den az (günde bir kez) olarak, katılma nöbeti süresi ise 1-3 dakika/gün, 3-5 dakika/gün ve 5 dakika/gün den uzun olarak gruplandırıldı. Katılma nöbeti sıklığı ve süresi; palatintonsil hipertrofi ve yumuşak damak evrelendirilmesi arasında karşılaştırılmalar yapıldı.

\section{Katılma Nöbet Tipleri:}

Soluk tip nöbet: Duyulan acı sonrasında (küçük yaralanmalar, kan görmek ya da kan alınması ve acı verici uyarılar) kısa bir çığlık, belirgin hipotoni, gevşeme ve sonrasında tüm vücut renginde solma olan çocuklar

Siyanotik tip nöbet: Uyarıcı bir etmen (acı, kızınlık, korku sonrası) sırasında apne olması ve deri renginin siyanotik renkte (morarma) değişen çocuklar şeklinde iki gruba ayrıldı.

Katılma nöbeti olan ve kontrol grubu tüm çocuklara yumuşak damak ve tonsiller hipertrofi evrelemesi yapıldı. Palatintonsillerin hem de yumuşak damağın derecelendirilmesinde farklı derecelendirme sistemleri kullanılsa da Friedman derecelendirme sisteminde orofarinks obstrüksiyonuna göre palatintonsillerin 4 adet hipertrofi derecesi;

- Evre 0: cerrahi olarak çıkarılmış tonsil

- Evre 1: tonsil, arka plika sınırını geçmemiş

- Evre 2: tonsil, arka plika arka duvarını aşmış.

- Evre 3: tonsil, plikaları aşmış ancak orta hattı geçmemiş

- Evre 4: kissing (öpüşen) tonsil görünüm olarak tanımlandı (7-8).

Yumuşak damak evrelemesi modifiye Friedman'a göre (mallompati-dil ağız içinde yapılan);

- Evre 1-Tüm uvula ve tonsiller görünüyor,

- Evre 2-Uvula görünüyor ancak tonsiller görünmüyor,

- Evre 3-Yumuşak damak görünüyor ancak uvula görünmüyor,

- Evre 4-Sadece sert damak görünüyor olarak evrelendirildi (9).

Katılma nöbeti olan hastaların yaşa ve cinsiyete göre nöbet süreleri, nöbet tipleri tonsil ve yumuşak damak evreleri kendi arasında ve kontrol grubu ile karşılaştırıldı.

\section{İstatistiksel yöntem:}

Verilerin analiz aşamasında SPSS 23.0 istatistik paket programı kullanılmıştır. Değerlendirme sonuçlarının tanımlayıcı istatistikleri; kategorik değişkenler için sayı ve yüzde, sayısal değişkenler için ortalama, standart sapma, minimum, maksimum olarak verilmiştir. Ölçümsel verilerin normal dağılıma uygunlukları OneSample Kolmogorov Simirnov testi ile değerlendirilmiş, verilerin normal dağılıma uyup uymadıkları tespit edilmiştir. Bağımsız grupların ölçümsel verileri Mann Whitney $U$ testi ve Kruskalwallis testi kullanılarak karşılaştırımıştır. Ölçümsel verilerin birbiriyle korelasyonu Spearman testi ile değerlendirilmiştir. Palatintonsil hipertrofisi ve yumuşak damak skorunun katılma nöbeti varlığını öngörmedeki tanısal karar verdiriciliği Receiver
Operating Characteristics (ROC) eğrisi analizi ile incelenmiştir. Anlamlı sınır değeri için sensitivite, spesifisite, pozitif prediktif değer, negatif prediktif değer hesaplandı. İstatistiksel anlamlılık seviyesi $\mathrm{p}<0.05$ olarak kabul edilmiştir.

\section{BULGULAR}

Hastaların yaşları 8 ay ile 56 ay arasında olup ortalama başlangıç

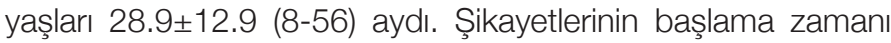
ise 13.14 \pm 9.78 aydı. 45 hastanın 22'si kız 23'ü erkekti. Kontrol grubu gönüllü bireyler K/E; 26/19'du. Kız ve erkekler arasında yaş dağılımı arasında farklıık yoktu. Katılma nöbeti olanların aile hikayelerinden ve videolarından katılma nöbetlerinin tipi \%84.4 siyanotik tipteydi. Çalışma grubundakilerin yaşları $(p=0.598)$, kilo $(p=0.652)$ ve boyları $(p=0.562)$ kontrol grubuna göre anlamlı farkılık göstermedi. Antropometrik ölçümleri Tablo l'de gösterildi.

Çalışma grubunun palatintonsil hipertrofisi evrelemesi \%45.0 Evre 1, \%36.8 Evre 2, \%15.8 Evre 3, \%2.4 Evre 4 iken kontrol grubunun ise \%72 Evre 1, \%11 Evre 2, \%11 Evre 3, \%6 Evre 4'dü. Yumuşak damak evrelemesine göre hasta grubunun \%13.2si Evre 1, \%28.9 Evre 2, \%50.0 Evre 3, \%7.9 ise Evre 4 iken kontrol grubunun ise \%60 Evre 1, \%18.6 Evre 2, \%16.6 Evre 3, \%4.4 Evre 4'dü. Siyanotik tipte nöbet ile tonsil büyüklüğü arasında pozitif korelasyon vardı (r:0.315, p:0.032). Siyanotik tipte nöbet tonsil büyüklüğü evre 2-3 olanlarda daha sıklıkla görüldü.

Katılma nöbeti olan çocukların tonsil evrelemeleri evre 1-2 (toplam \%81.8) iken yumuşak damak evrelemeleri evre 2-3 (toplam \% 78.9)'du ve kontrol grubu ile anlamlı farklılık vardı (p:0.000). Tonsil büyüklüğü Evre 1-2 olan hastaların nöbet süreleri 1-3 dakika iken, yumuşak damak evresi Evre 2-3 olan hastaların nöbet süresi 3-5 dakikaydı. Tonsil büyüklüğü ve yumuşak damak evrelemesi arttıkça katılma nöbetleri sıklığında ve sayısında artış vardı. Tonsil hipertrofisi ve yumuşak damak evrelemesine göre nöbet süresindeki değișimler Tablo I'de katılma nöbeti olan çocukarın nöbet süresi ve sıklıklarının palatintonsil hipertrofisi ve yumuşak damak evrelemesine göre dağılımı Tablo ıll'de verildi. Katılma nöbeti sıklığı her gün \%33'ünde, haftada iki kez \%49.5'inde haftada iki kez den az ise \%16.5 oranında görülmekteydi. Katılma nöbeti süresi 1-3

Tablo I: Katılma nöbeti ve kontrol grubunun antropometrik ve demografik özellikleri.

\begin{tabular}{l|c|c|c}
\hline & $\begin{array}{c}\text { Katılma nöbeti olan } \\
\text { çocuklar n(45) }\end{array}$ & $\begin{array}{c}\text { Kontrol } \\
\text { grubu n(45) }\end{array}$ & p \\
\hline Yaş (ay) & $8.16 \pm 12.8$ & $20.85 \pm 10.25$ & 0.598 \\
\hline Cinsiyet (K/E) & $22 / 23$ & $26 / 19$ & \\
\hline Kilo (kg) & $13.5 \pm 10.8$ & $12.5 \pm 11.8$ & 0.652 \\
\hline Boy (cm) & $88.5 \pm 12.8$ & $86.8 \pm 11.8$ & 0.562 \\
\hline
\end{tabular}

Ortalama standart sapma gösterimi; ortalama \pm standart sapma, $p<0.05$ anlamlı 
Tablo II: Katılma nöbeti olan çocukların palatintonsil ve yumuşak damak hipertrofisinin nöbet süresine olan etkisinin karşılaştırıması ve evrelemelere göre kontrol grubuyla sayısal olarak değerlendirilmesi.

\begin{tabular}{|c|c|c|c|c|c|}
\hline & $\begin{array}{c}\text { Katılma nöbeti olan çocukların } \\
\text { palatintonsil hipertrofisi } \\
\text { evrelemesi } \\
\text { n (Nöbet Süresi) }\end{array}$ & $\begin{array}{c}\text { Kontrol } \\
\text { grubu } \\
\text { n }\end{array}$ & $\begin{array}{c}\text { Katılma nöbeti olan çocukların } \\
\text { yumuşak damak evrelemesi } \\
\text { n (Nöbet Süresi) }\end{array}$ & $\begin{array}{l}\text { Kontrol } \\
\text { grubu } \\
\text { n }\end{array}$ & p \\
\hline \multicolumn{6}{|c|}{ (2) (1) } \\
\hline Evre 1 & $26(3.04 \pm 1.07)$ & 30 & $6(2.04 \pm 1.03)$ & 27 & 0.026 \\
\hline Evre 2 & $11(3.41 \pm 1.86)$ & 13 & $14(3.94 \pm 1.27)$ & 15 & 0.036 \\
\hline Evre 3 & $6(4.5 \pm 0.05)$ & 2 & $19(4.9 \pm 0.91)$ & 3 & 0.006 \\
\hline Evre 4 & $2(5.04 \pm 0.12)$ & - & $6(5.20 \pm 1.07)$ & - & 0.048 \\
\hline
\end{tabular}

n: hasta sayısı, $\boldsymbol{p}$ değeri: katılma nöbeti olan palatintonsil hipertrofisi ve yumuşak damak evresi ile çocukların nöbet sürelerinin karşılaştırılması, $p<0.05$ anlamlı

Tablo III: Katıma nöbeti olan çocukların palatintonsil ve yumuşak damak evrelemlerinin nöbet sıklığı ve süresine göre dağılımları.

\begin{tabular}{|c|c|c|c|c|c|}
\hline Palatintonsil Evrelemesi (n) & Evre 1 (n: 26) & Evre 2 (n:11) & Evre 3 (n:6) & Evre 4 (n:2) & $\mathrm{p}$ \\
\hline $\begin{array}{l}\text { Nöbet sıklığı } \\
\text { Her gün } \\
\text { Haftada iki gün } \\
\text { Haftada iki günden az }\end{array}$ & $\begin{array}{c}5 \\
14 \\
6\end{array}$ & $\begin{array}{l}5 \\
5 \\
1\end{array}$ & $\begin{array}{l}3 \\
2 \\
1\end{array}$ & $\begin{array}{l}1 \\
1 \\
1\end{array}$ & $\begin{array}{l}0.025^{1,2 *} \\
0.012^{1,2 *} \\
0.003^{1,2 *}\end{array}$ \\
\hline $\begin{array}{l}\text { Nöbet süresi } \\
\text { 1-3 dakika/gün } \\
\text { 3-5 dakika/gün } \\
\text { >5 dakika/gün } \\
\text { Yumuşak Damak Evrelemesi (n) }\end{array}$ & $\begin{array}{c}10 \\
16 \\
- \\
\text { Evre } 1(\mathrm{n}: 6)\end{array}$ & $\begin{array}{c}2 \\
8 \\
1 \\
\text { Evre } 2(n: 14)\end{array}$ & $\begin{array}{c}1 \\
4 \\
1 \\
\text { Evre } 3(n: 19)\end{array}$ & $\begin{array}{c}- \\
- \\
2 \\
\text { Evre } 4(n: 6)\end{array}$ & $\begin{array}{l}0.025^{1,2 *} \\
0.012^{1,2 \star} \\
0.003^{3,4 *}\end{array}$ \\
\hline $\begin{array}{l}\text { Nöbet sıklığı } \\
\text { Her gün } \\
\text { Haftada iki gün } \\
\text { Haftada iki günden az }\end{array}$ & $\begin{array}{l}- \\
5 \\
1\end{array}$ & $\begin{array}{l}3 \\
8 \\
2\end{array}$ & $\begin{array}{l}11 \\
7 \\
2\end{array}$ & $\begin{array}{l}- \\
2 \\
3\end{array}$ & $\begin{array}{l}0.025^{2,3 *} \\
0.012^{2,3 *} \\
0.003^{2,4 *} \\
0.002^{2,3 *}\end{array}$ \\
\hline $\begin{array}{l}\text { Nöbet süresi } \\
\text { 1-3 dakika/gün } \\
3-5 \text { dakika/gün } \\
>5 \text { dakika/gün }\end{array}$ & $\begin{array}{l}1 \\
2 \\
3\end{array}$ & $\begin{array}{c}2 \\
12 \\
-\end{array}$ & $\begin{array}{c}5 \\
13 \\
1\end{array}$ & $\begin{array}{l}5 \\
1 \\
-\end{array}$ & $\begin{array}{l}0.025^{3,4 *} \\
0.012^{2,3 *} \\
0.003^{1,3 *}\end{array}$ \\
\hline
\end{tabular}

n: hasta sayısı, ${ }^{\mathbf{1 *}}$ :Evre 1 ile Evre 2 arasında, ${ }^{2 *}$ :Evre 1 ile Evre 3 arasında, ${ }^{3 *}$ : Evre 2 ile Evre 3 arasında, ${ }^{4 *}$ : Evre 3 ile Evre 4 arasındadır.

dakika olan 13 (\%31) çocuk, 3-5 dakika arasında olan 28 (\%62) çocuk ve $>5$ dakika ise 4 (\%7) çocuk hasta vardı. Cinsiyet ve yaş açısından nöbet süresinde arasında anlamlı bir farklllık yoktu. Katıma nöbeti süresi ortalama $3.5 \pm 1.3$ dakikaydı. Tonsil büyüklüğü ile nöbeti süresi arasında pozitif korelasyon vardı. Aynı zamanda yumuşak damak evrelemesi ile nöbet süresi arasında da daha güçlü bir korelasyon sırasıyla mevcuttu (r:0.459, p:0.000; r:0.734, p:0,000). Aksine nöbet sıklı̆ı ile nöbet süresi arasında negatif bir korelasyon mevcuttu (r:-0.416, p:0.000). Nöbet sıklığı her gün olan çocukların tonsil ve yumuşak damak evreleri 2-3 iken haftada iki günden daha da az olanların evre $1-2$ 'di (p:0.002)

Palatintonsil hipertrofisi ve yumuşak damak evrelemesinin katıma nöbetini öngörmedeki riski açısından Palatintonsil lerevreleme kontrol grubuna göre istatistiksel olarak anlamlı olsa da asıl etken yumuşak damak evrelemesi evre 2 ve üzerinde olan çocuklarda risk 1.5 kat yüksek olarak belirlendi. Yumuşak damak evresinin tanısal karar verdiriciliği, sensivitesi \%86.7, spesifitesi \%60.0 pozitif prediktif değeri \%68.4, negatif prediktif değeri \%81.8'di. ROC eğrisi analizi ile şekil 1'de verildi.

\section{TARTIŞMA}

Katılma nöbetleri çocukluk çağında sık görülen epileptik olmayan paroksismal bir olay olsa da ailelere ve çocuğun bakımı ile ilgilenen kişilere oldukça endişe verici bir durumdur. Pediatri pratiğinde de sıklıkla görülmektedir. Ancak etiyolojisinde demir eksikliği anemisi, selenyum eksikliği ve oksidatif stres yer alsa da tam olarak aydınlatılamamıştır ve de oluşan sekonder hipoksi sorunların ana nedeni gibi görünmektedir (6,12-14). Demir eksikliği anemisi olmayan sık enfeksiyon geçirmeyen çocuklarda katıma nöbetinin etiyolojisinde hava yolunun ayrıntı muayenesinin çok önemli olduğunu düşünüyoruz. Sadece tonsil hipertrofisi rutin muayenede yapılmakta ancak yumuşak damak muayenesi gerek muayene güçlüğü gerekse hasta uyumu ile ilgili olarak zorluklar yaşatmaktadır. Biz çalışmamızda sık enfeksiyon geçirmeyen ve demir eksikliği anemisi olmayan katıma nöbeti olan çocuk hastalarda ilk kez palatintonsil hipertrofininve yumuşak damak evrelemesinin önemini göstermeyi amaçladık.

Havayolu tıkanıklarının çocukluk yaş grubunda ortaya çıkardığı sık enfeksiyon geçirme, uyku kalitesinde bozulma 


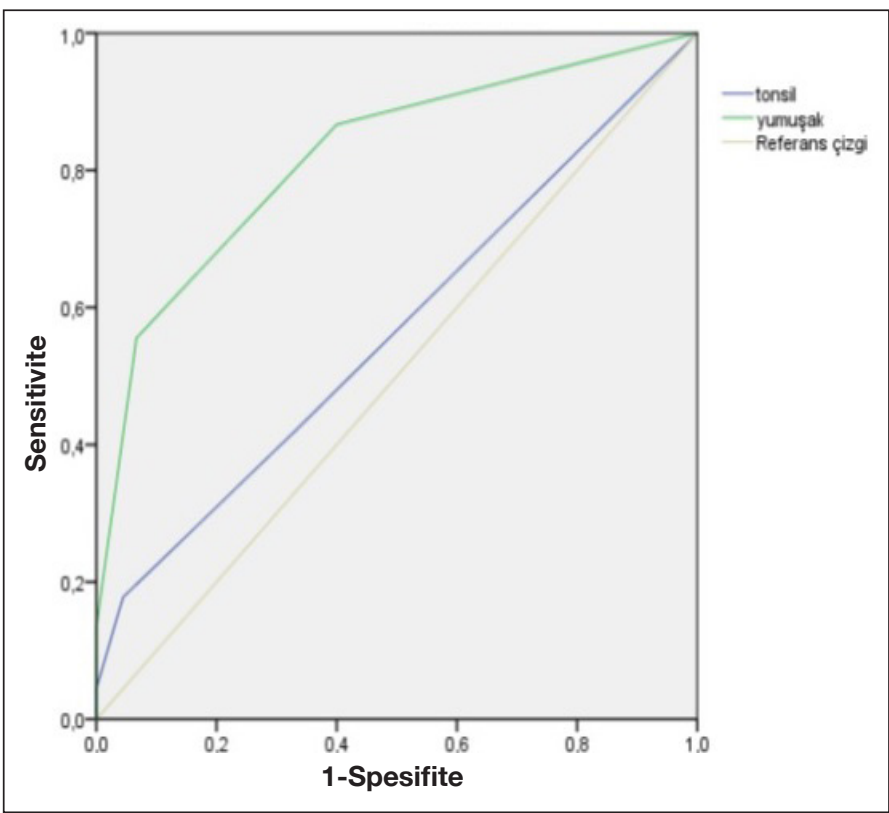

Şekil 1.Katılma nöbeti olan çocukların palatintonsil hipertrofi ve yumuşak damak evrelemesinin ROC analizi ile gösterimi.

Katılma nöbeti olan çocukların palatintonsil hipertrofi ve yumuşak damak evrelemesinin nöbet süresinin uzamasındaki etkisinin öngörebilirliliğinin ROC analizi ile gösterimi (Palatintonsil hipertrofisi AUC: 0.566 [Cl: 0.447-0.685]; Yumuşak damak evrelemesi AUC: 0.820 [Cl: 0.732$0.908]$

gibi durumların dışında nefes alma problemleri de önemli bir sorundur. Çocukluk yaş grubunda özellikle obstriktif uyku apnesi (OSA) olan çocuklarda tonsiller adeniodal ve yumuşak damak patolojileri görülmektedir $(15,16)$. Eğer hastanın anatomik yapısı asemptomatikse erken yaș grubunda sorun olușturmayabilir. Biz ilginç olarak katılma nöbeti olan çocuklarda tonsilhipertrofisi Evre 2-3 \%78.9 kontrol grubunun Evre 1-2 \%81.8 iken yumuşak damak evrelemesi kontrol grubunun \%32.2, katılma nöbeti olanların ise \%78.9 Evre 2-3 hipertrofilerinin mevcut idi ve katılma nöbeti olan çocuklarda sağlıklı çocuklara göre özellikle de yumuşak damak evrelemesinin daha belirgin olduğu görüldü.

Tonsil sağlıklı çocuklarda dinamik ve yașla birlikte de değișiklikler gösteren lenfoid bir yapıdır. Tonsiller hipertrofi ağızdan soluma, nazal konjesyon, nazone konușma, horlama, emosyonel değișiklikler ve de kötü beyin gelișimi ile ilgilidir (17). Emosyonel değişikliklerin ortak özellik olması oldukça ilginçtir. Emosyonel durumla tetiklenen katılma nöbeti olan çocuklarda katıma nöbeti olanların kontrol grubuna göre tonsil evrelerinin daha ileri evre olduğunu tespit ettik ancak nöbet sürelerinde uzama ve hipertrofi evrelemesinde önemli farkllığı yumuşak damak evrelemesi oluşturdu. Yumuşak damak evresi arttıkça da nöbet sürelerini de önemli oranda uzamaktaydı.

Yumuşak damak konuşma, nefes alma, yutkunma gibi ișlemlerin en önemli anatomik yapısından biridir. Yumuşak damak hareketli olmasından dolayı yüksek fonksiyonel özelliklere sahiptir. Erișkin dönemde OSA gibiönemli bir uyku probleminin de patolojisi kabul görmüştür (18). Ding Xiao-Xu ve ark. (15) çalışmasında evre 3 ve üzeri tonsil hipertrofisi olan 150 OSA'lı çocuk rastgele deney ve kontrol grubu olarak ayrımıştır. Deney grubuna adenoidektomi, tonsillektomi ve yumuşak damak-faringoplasti uygulanmış olup, kontrol grubuna adenoidektomi ve tonsillektomi uygulanmıștir. Gösterildiği gibi adenotonsillektomiye ek olarak yumuşak damak onarımının çocuklarda hem yaşam kalitesi, emosyonel durum hem de diğer sorunların anlamlı olarak daha düzeldiği görülmüştür. Ancak çocukluk çağındaki nefes tutma atakları ile seyreden katıma nöbeti olan çocuklarda yeri hiç tartışılmamıştır. Çalıșmamızda nefes tutma atakları sırasında yumuşak damak evresi 2-3 olan çocukların nöbet süreleri oldukça uzundur. Katıma nöbeti olan çocukların havayolu muayenelerinin ayrıntı yapılması katılma nöbetinin çocuk hastada yönetiminde önemli bir yeri bir yeri olacaktır. Belki de takip ve tedavide kolaylik sağlayacak ve sekonder hipoksiye maruziyeti önemli oranda azaltacağını düşünmekteyiz. Yumuşak damak patolojisinin tanımlanması ve gerekirse erken cerrahi müdahele de çalışmamızda olduğu gibi katılma nöbeti olan çocuklarda da ayrıca önemli bir yere sahiptir.

Erken çocukluk döneminde sağlıklı bir beyin gelişimi için gerekli olan oksijenizasyonun sağlanması için tonsiller hipertrofi ve yumuşak damak yapısı önemli ve erken dönemde müdahele edilmesi gerekli bir durumdur. Hatta nefes tutma ile seyirli katılma nöbetleri açısından erken cerrahi müdahale ve onarım için önemli bir neden oluşturabilir.

Sonuç olarak bu çalışmanın sonucunda demir eksikliği anemisi ve sık enfeksiyonu geçirme șikayeti olmayan katıma nöbeti olan çocuk hastalarda kontrol grubuna oranla palatintonsil hipertrofinin belirgin olduğunu ancak yumuşak damak evrelemesinin daha ileri evrelerde olduğunu gösterdik. Bu çalıșma katılma nöbeti etyolojisinde ve nöbet süresinin uzamasının ileri evre yumuşak damak ve palatintonsil hipertrofi bulgusu ile ilişkisinin olabileceğini gösteren ilk çalıșmadır. Sonuç olarak katılma nöbeti olan hastalarda palatintonsil ve yumuşak damak incelenmesi çocuklarda horlama ve uyku problemleri olmasa da sorgulanmalı ve yumuşak damak evrelemesine muayenede yer verilmelidir. Bu konu ile ilgili yapılacak daha geniş çaplı çalışmalara intiyaç vardır.

\section{KAYNAKLAR}

1. Di Mario FJ. Breath-holding spells in childhood. Curr Probl Pediatr 1999;29:281-300.

2. Carman KB, Ekici A, Yimenicioglu S, Arslantas D, Yakut A. Breath holding spells: point prevalence and associated factors among Turkish children. Pediatr Int 2013;55:328-31.

3. Colina KF, Abelson HT. Resolution of breath-holding spells with treatment of concomitant anaemia. J Pediatr 1995;126:395-97.

4. Daoud AS, Batieha A, al-Sheyyab M, Abuekteish F, Hijazi S. Effectiveness of iron therapy on breath-holding spells. J Pediatr 1997;130:547-50.

5. Mattie-Luksic M, Javornisky G, Di Mario FJ. Assessment of stress in mothers of children with severe breath-holding spells. Pediatrics 2000;106:1-5. 
6. Saad K, Farghaly Hikma S, Badry R. Othman Hisham A.K, Selenium and antioxidant levels decreased in blood of children with breathe holding spells. J Child Neurol 2014;29:1339-43.

7. Friedman M, Tanyeri H. Clinical Predictors of Obstructive Sleep Apnea. Laryngoscope 2009;109:1901-7.

8. Friedman M, Ibrahim H, Bass L. Clinical staging for sleep-disordered breathing. Otolaryngol Head Neck Surg 2020;127:12-3.

9. Mallampati S.R, Gatt S.P,Gugino L.D. A clinical sign to predict difficult intubation: a prospective study. Can Anaesth Soc J 1985;32:429-34.

10. Paparella M, Shumrick D.A, Gluckman J.L, Meyerhof W.L, Alan D, Kornblut A. Nonneoplastic diseases of the tonsils and adenoids. Otorhinolaryngology 1991;3:2129-47.

11. Isler, M, Delibas, N, Guclu, M, Gultekin, F, Sutcu, R, Bahceci, M, Kosar, A. Superoxidedismutase and glutathione peroxidase in erythrocytes of patients with iron deficiency anemia: effects of different treatment modalities. CroatMed J 2002;43:16-19.

12. Calik, M, Abuhandan, M, Aycicek, A, Taskin, A, Selek, S, Iscan, A. Increased oxidant status in children with breath-holding spells. Childs Nerv Syst 2013;29:1015-9.
13. KhaledSaad, MD, Hikma S. Farghaly, MD, RedaBadry, MD, Hisham A.K Othman, MD. Selenium and antioxidant levels decreased in blood of children with breathe holding spells. Journal of Child Neurology 2014;29:1339-43.

14. Daoud AS, Batieha A, al-Sheyyab M, Abuekteish F, Hijazi S. Effectiveness of iron therapy on breath-holding spells. J Pediatr 1997;130:547-50.

15. Ding Xiao-Xu, Zhao Lan-Qing, Cui Xiang-Guo, Yin Yang, Yang Huai-An. Clinical observation of soft palate-pharyngoplasty in the treatment of obstructive sleep apnea hypopnea syndrome in children. World J Clin Cases 2020;26:679-88.

16. Deepti Sinha D, Guilleminault C. Sleep disordered breathing in children Indian J Med Res 2010;131:311-20.

17. Kurnatowski P, Putynski L, Łapienis M, Kowalska B. Physical and emotional disturbances in children with adenotonsillar hypertrophy. J Laryngol Otol 2008;122:931-35.

18. Kapur V.K, Auckley D.H, Chowdhuri S, Kuhlmann D.C, Mehra R,. Ramar Kharrod C.G. Clinical Practice Guideline for Diagnostic Testing for Adult Obstructive Sleep Apnea: An American Academy of Sleep Medicine Clinical Practice Guideline. J Clin Sleep Med 2017;13:479-504. 